
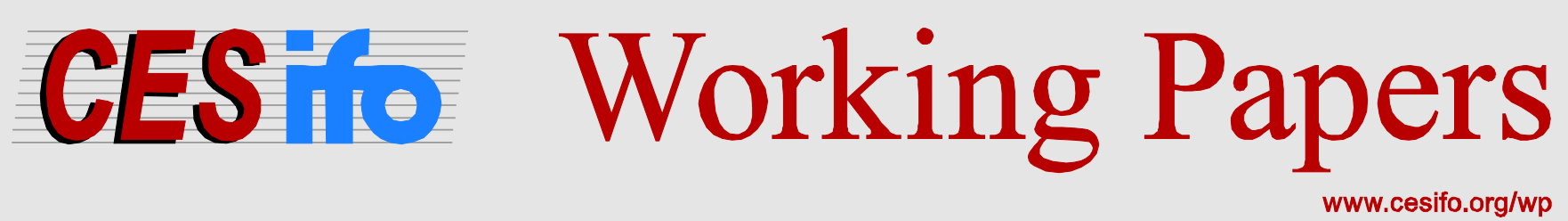

\title{
Time Inconsistency and Retirement Choice
}

\author{
T. Scott Findley \\ Frank N. Caliendo
}

CESIFO WORKING PAPER NO. 5208

CATEGORY 13: BEHAVIOURAL ECONOMICS

FEBRUARY 2015

An electronic version of the paper may be downloaded

- from the SSRN website:

- from the RePEc website:

- from the CESifo website:

wWw.SSRN.com

www.RePEc.org

www.CESifo-group.org/wp 


\title{
Time Inconsistency and Retirement Choice
}

\begin{abstract}
Hyperbolic discounting with naiveté is widely believed to provide a better explanation than exponential discounting of why people borrow so much and why they wait so long to save for retirement. We reach a different set of conclusions. We show that if financial planning is enriched to include the choice of when to retire, then naïve hyperbolic discounters may borrow far less and start saving for retirement significantly earlier than exponential discounters.

to provide a better explanation than
and why they wait so long to save for
We show that if financial planning is
gnificantly earlier than exponential
\end{abstract}

JEL-Code: C610, D030, D910.

Keywords: hyperbolic discounting, naiveté, retirement choice, time inconsistency, life-cycle consumption and saving.

\author{
T. Scott Findley* \\ Utah State University / USA \\ tscott.findley@usu.edu
}




\section{Introduction}

A common claim is that hyperbolic discounting provides a better answer than exponential discounting to the questions of why people borrow so much and why they wait so long to save for retirement. For instance, Angeletos, Laibson, Repetto, Tobacman, and Weinberg (2000, 2001) and Laibson, Repetto, and Tobacman (2007) conclude that hyperbolic discounting provides a better explanation of the aggressive borrowing observed in the data, regardless of whether individuals are naive or sophisticated. And O'Donoghue and Rabin (1999) conclude that hyperbolic discounting (with naiveté) better accounts for delayed implementation of retirement saving plans.

Our paper reaches a different set of conclusions. While past studies abstract from the choice of when to retire, we show that if financial planning is enriched to include this margin, then naive hyperbolic discounters may borrow far less and start saving for retirement significantly earlier than exponential discounters. This is true even though hyperbolic discounters fall short of their saving goals.

To show this we extend Diamond and Köszegi's (2003) endogenous retirement model in two ways: first, we use continuous time rather than three periods to capture richer saving dynamics; and second, we study naiveté rather than sophistication which means the individual constantly revises all dimensions of his financial plans. Not only does the individual fail to follow through with past consumption and saving plans, but he also makes and then breaks his plans about his future retirement age. In our preferred parameterization, hyperbolic discounters incur about half as much debt and start saving several years earlier during the working phase than exponential discounters. Moreover, assets at retirement are roughly equivalent.

These counter-conventional findings come from the interplay between the dual layers of time inconsistency. While they are young, hyperbolic discounters make plans to retire early but then fail to save as much as they had planned. They respond by delaying their future retirement age. Actual retirement occurs when it is no longer desirable to postpone retirement. In our baseline calibration, hyperbolic discounters initially plan to retire at age 61 but then they delay until ultimately retiring at age 66. In contrast, exponential discounters correctly anticipate their retirement age which we calibrate to 66 to make a fair comparison. Even though hyperbolic discounters fall short of their saving goals, they borrow relatively little and save relatively early because their decisions are based on mistaken beliefs about early retirement. Therefore, almost paradoxically, time-inconsistent preferences can produce "provident" savings outcomes.

Our findings may be particularly surprising given that one may have expected naive individuals to retire earlier than planned as they succumb to self-control problems. In fact, naive individuals will indeed retire earlier than planned if they are artificially endowed at each point in time with "commitment assets" (assets corresponding to the first plan). But in a richer model with dual layers of time inconsistency where the individual falls short of past saving goals, the temptation to retire early is dominated by the desire to postpone retirement in order to buy extra time to earn and save.

Our findings may have practical implications. It has become fashionable to justify government intervention in household financial planning by pointing to time-inconsistent preferences (i.e., to a failure to reach past saving goals). However, past saving goals may be based 
on mistaken beliefs about the age of retirement. If so, then there is no obvious argument for helping people to reach their past goals. Moreover, the argument for intervention is further weakened if individuals with time-inconsistent preferences get out of debt quicker, start saving earlier, and accumulate roughly the same assets for retirement as otherwise identical individuals with standard preferences.

\section{Continuous-Time Model with Naiveté}

\subsection{Notation}

We abstract to a stylized setting. Age is continuous and indexed by $t$. The individual starts work at $t=0$, retires endogenously at $t=T$, and passes away at $t=\bar{T}$. He discounts future utility with the function $F(x)$ for a delay of length $x$, where $F(0)=1$ and $d F(x) / d x<0$. Consumption is $c(t)$ and holdings of a zero-interest asset are $k(t)$. The asset can be positive (savings) or negative (debt). We assume $k(0)=k(\bar{T})=0$. The style of our labor market follows Diamond and Köszegi (2003), Heijdra and Romp (2009), and Dybvig and Liu (2010): everyone starts out a worker, labor is indivisible during the working years, and retirement is irreversible. The period utility function when working is $\ln c(t)-\psi$ where $\psi>0$, and $\ln c(t)$ when retired. We have worked out numerous, more complicated versions of our model with additional features such as part-time work after retirement, social security taxes and benefits, positive returns on savings, and CRRA utility. But these additional features do not alter our conclusions, so we present this stylized version that has an analytical solution.

Formally,

$$
\frac{d k(t)}{d t}=\left\{\begin{array}{c}
1-c(t), \text { for } t \in[0, T] \\
-c(t), \text { for } t \in[T, \bar{T}]
\end{array}\right.
$$

We denote planned quantities with a hat $(\wedge)$ and actual quantities with an asterisk $(*)$.

\subsection{Financial Planning}

At any $t$ before retirement, the individual makes a financial plan involving consumption and saving allocations and an intended age of retirement,

$$
\max _{\{c(v)\}, T \in[t, \bar{T}]}\left\{\int_{t}^{\bar{T}} F(v-t)[\ln c(v)-\mathbf{1}\{v \in[t, T]\} \psi] d v\right\},
$$

subject to

$$
\frac{d k(v)}{d v}=\left\{\begin{array}{c}
1-c(v), \text { for } v \in[t, T] \\
-c(v), \text { for } v \in[T, \bar{T}]
\end{array}\right.
$$

with $k(t)=k^{*}(t)$ and $k(\bar{T})=0$.

The solution, as a function of $k^{*}(t)$, from the perspective of any planning instant $t$, is

$$
\hat{c}(v \mid t)=\frac{k^{*}(t)+\hat{T}(t)-t}{A(t)} F(v-t), \text { for } v \in[t, \bar{T}]
$$




$$
\begin{gathered}
\hat{T}(t)=\underset{T \in[t, \bar{T}]}{\arg \max }\left\{\ln \left[k^{*}(t)+T-t\right] A(t)-\psi \int_{t}^{T} F(v-t) d v\right\}, \\
A(t) \equiv \int_{t}^{\bar{T}} F(v-t) d v .
\end{gathered}
$$

\subsection{The Path Actually Followed}

The naive individual believes that his future selves will adhere to the plan denoted above, yet his actual consumption coincides with his planned consumption only at the instant the plan is formulated. Actual consumption at time $t$ is found by replacing $v$ in (4) with $t$,

$$
c^{*}(t)=\hat{c}(t \mid t)=\frac{k^{*}(t)+\hat{T}(t)-t}{A(t)} .
$$

Equation (7) is the envelope of initial values from infinitely many planned consumption paths. Finally, actual retirement $T^{*}$ solves the implicit function

$$
\hat{T}(t)=t
$$

\subsection{Closed-Form Solution}

Let $F(x)=(1+\beta x)^{-1}$. At any age $t$ during the working period, the intended age of retirement $\hat{T}(t)$ and the actual consumption and savings paths $c^{*}(t)$ and $k^{*}(t)$ are

$$
\begin{gathered}
\hat{T}(t)=\psi Z(t) \int_{0}^{t}[1+Z(v)] \exp \left[-\int_{v}^{t} \beta Z(j) d j\right] d v-A(t) Z(t)+t, \\
c^{*}(t)=\beta Z(t) \int_{0}^{t}[1+Z(v)] \exp \left[-\int_{v}^{t} \beta Z(j) d j\right] d v-Z(t), \\
k^{*}(t)=\int_{0}^{t}[1+Z(v)] \exp \left[-\int_{v}^{t} \beta Z(j) d j\right] d v \\
Z(t) \equiv \frac{1}{\beta A(t)-\psi} .
\end{gathered}
$$

See the Appendix for the derivation.

\section{Numerical Examples and Discussion}

\subsection{Hyperbolic Discounting}

An individual starts work at age 25 and passes away at 80 , hence $\bar{T}=55$. We set $\beta=3 \%$, though our results are robust to larger values of $\beta$. We calibrate $\psi=1.872$ to generate actual retirement at age 66 . 
Figure 1 depicts $\hat{T}(t)$, the timepath for the intended age of retirement. The individual works if the planned retirement age exceeds his current age. The individual actually retires when the planned age of retirement is equal to his current age. In particular, the individual ultimately delays retirement by 4.8 years.

We plot two worklife consumption profiles in Figure 2 to highlight the implications of time inconsistency in retirement choice. The profiles correspond to hyperbolic discounting with and without endogenous retirement. We set retirement to 66 in the version with exogenous retirement to conduct a fair comparison with equal lifetime earnings. Clearly, intentions about the future age of retirement exert significant slope and level effects on consumption.

The differences in worklife consumption become more pronounced with larger values of $\beta$. For example, 66 remains the age of actual retirement for $\beta=6 \%$ as long as $\psi$ is calibrated to 2.3015. Figure 3 demonstrates that the degree of time inconsistency in planned retirement becomes more severe relative to the baseline.

Figure 4 plots the bias in consumption that arises when retirement is exogenously imposed, defined as the ratio of consumption with exogenous retirement to consumption with endogenous retirement. Consumption can be overstated by as much as $40 \%$ when young and understated by as much as $20 \%$ when older if retirement choice is ignored.

\subsection{Hyperbolic versus Exponential Discounting}

To understand the consequences of preference reversals induced by hyperbolic discounting, it is logical to compare to a model without such reversals (i.e., exponential discounting, $\left.F(x)=e^{-\rho x}\right)$. We select the parameters of the alternative discount functions so that actual retirement occurs at the same age. This allows us to ask the following question: given an actual retirement age, what do the alternative discount functions predict about debt and savings before that age? If parameters are selected any other way such that the age of actual retirement is different across discount functions, then any comparison of savings outcomes is contaminated by differences in total lifetime earnings. Given $\psi=1.872$, retirement under exponential discounting occurs at 66 if $\rho=2.072 \%$.

Figure 5 illustrates our main findings. Relative to exponential discounting, hyperbolic discounting leads to approximately half as much borrowing during the early years of the worklife, earlier saving for retirement by several years, and approximately the same balance in the savings asset at retirement. This is surprising since the hyperbolic discounter persistently fails to follow his saving plans while the exponential discounter never deviates from his plan.

Time inconsistency in retirement choice is responsible for these outcomes. Even though the actual age of retirement is identical, the hyperbolic discounter intends to be retired earlier than the exponential discounter. Early saving and restrained borrowing follow naturally since an earlier intended age of retirement requires an aggressive saving plan to finance inflated retirement needs. Figure 6 is analogous to Figure 5, but it includes the asset path of an otherwise identical hyperbolic discounter who retires exogenously at 66 . Notice that the hyperbolic discounter borrows more than the exponential discounter and also starts saving later for retirement in the absence of retirement choice. This exercise lines up with conventional wisdom, yet it reinforces our central message.

Our findings are robust if the model is re-calibrated to alternative ages of actual retirement (e.g., ages 63, 69, 72). Hyperbolic discounting with endogenous retirement consistently 
leads to less borrowing, earlier saving, and similar resources at retirement, relative to exponential discounting. This robustness analysis is reported in Tables $1 \mathrm{a}$ and $1 \mathrm{~b}$. We have not identified any calibration that reverses our findings while making reasonable predictions about the age of actual retirement.

Finally, there exists a non-trivial bias against our findings given that the exponential discounter is more patient than the hyperbolic discounter for every $(\beta, \rho)$ pair that we consider. By this we mean that the area under the exponential discount function is strictly larger than the area under the hyperbolic function for all $t$. The area under a discount function, $A(t)$ from (6), is a measure of the overall level of patience (e.g., Myerson, Green, and Warusawitharana 2001; Caliendo and Findley 2014). Therefore, in our numerical exercises the hyperbolic discounter is strictly more impatient than the exponential discounter from every vantage point. Yet despite this bias, the hyperbolic discounter borrows less, starts saving earlier, and arrives at retirement with nearly the same level of savings.

\section{Appendix: Derivation of Closed-From Solution}

From (5) we define the value function from the perspective of any pre-retirement vantage point $t$ as

$$
V(T) \equiv \ln \left[k^{*}(t)+T-t\right] A(t)-\psi \int_{t}^{T} F(v-t) d v .
$$

Using the hyperbolic discount function $F(x)=(1+\beta x)^{-1}$, differentiate (13) with respect to $T$ to obtain a unique stationary point

$$
\hat{T}(t)=\frac{\psi\left[k^{*}(t)-t\right]-[1-\beta t] A(t)}{\beta A(t)-\psi} .
$$

Next insert (14) into (7) and use the definition of $Z(t)$

$$
c^{*}(t)=\beta Z(t) k^{*}(t)-Z(t) .
$$

Insert (15) into the top equation in (1)

$$
\frac{d k^{*}(t)}{d t}=1-\beta Z(t) k^{*}(t)+Z(t)
$$

and solve (16) using the boundary condition $k^{*}(0)=0$ to obtain the actual savings account balance (11) during the working period. Equations (9) and (10) follow by inserting (11) into (14) and (15).

Finally, we prove next that the stationary point $\hat{T}(t)$ does indeed correspond to a maximum and not a minimum. To illustrate, we break into two cases. Case 1 is any point in time for which $k^{*}(t) \leq 0$. Case 2 is the reverse, $k^{*}(t)>0$.

Case 1. The value function $V(T)$ is defined only for $T>t-k^{*}(t) \equiv t^{\prime}$. For an arbitrary small positive scalar $\epsilon$,

$$
\frac{d V\left(t^{\prime}+\epsilon\right)}{d T}=\frac{A(t)}{\epsilon}-\psi F\left(\epsilon-k^{*}(t)\right)
$$


Making $\epsilon$ arbitrarily small makes $d V\left(t^{\prime}+\epsilon\right) / d T$ arbitrarily large and positive. Hence, the value function is increasing in $T$ at the point $T=t^{\prime}+\epsilon$, and since the first-order condition $d V(T) / d T=0$ has only one root $(\hat{T}(t))$, it must correspond to a local maximum rather than a minimum.

Case 2. Note that,

$$
\text { if at time } t, k^{*}(t)=\frac{A(t)}{\psi} \text {, then } \frac{d V(t)}{d T}=0 \text { and } \hat{T}(t)=t,
$$

if at time $t, k^{*}(t)<\frac{A(t)}{\psi}$, then $\frac{d V(t)}{d T}>0$ and $\hat{T}(t)>t$ is a local max.

\section{References}

Angeletos, Marios, David Laibson, Andrea Repetto, Jeremy Tobacman, and Stephen Weinberg (2000). Hyperbolic Discounting, Wealth Accumulation, and Consumption. Working Paper.

Angeletos, George-Marios, David Laibson, Andrea Repetto, Jeremy Tobacman, and Stephen Weinberg (2001). The Hyperbolic Consumption Model: Calibration, Simulation, and Empirical Evaluation. Journal of Economic Perspectives 15(3), 47-68.

Caliendo, Frank N. and T. Scott Findley (2014). Discount Functions and Self-Control Problems. Economics Letters 122(3), 416-419.

Diamond, Peter and Botond Köszegi (2003). Quasi-hyperbolic Discounting and Retirement. Journal of Public Economics 87(9-10), 1839-1872.

Dybvig, Philip H. and Hong Liu (2010). Lifetime Consumption and Investment: Retirement and Constrained Borrowing. Journal of Economic Theory 145(3), 885-907.

Heijdra, Ben J. and Ward E. Romp (2009). Retirement, Pensions, and Ageing. Journal of Public Economics 93(3-4), 586-604.

Laibson, David I., Andrea Repetto, and Jeremy Tobacman (2007). Estimating Discount Functions with Consumption Choices over the Life Cycle. NBER Working Paper Series, Working Paper No. 13314.

Myerson, Joel, Leonard Green, and Missaka Warusawitharana (2001). Area Under the Curve as a Measure of Discounting. Journal of the Experimental Analysis of Behavior $76(2), 235-243$.

O'Donoghue, Ted and Matthew Rabin (1999). Procrastination in Preparing for Retirement. In Behavioral Dimensions of Retirement Economics, edited by Henry Aaron. Washington D.C.: Brookings Institution Press and Russell Sage Foundation, 125-160. 
Table 1a. Calibration of Parameters for Alternative Ages of Retirement

disutility of work, $\psi$

\begin{tabular}{cccc} 
age 63 & age 66 (baseline) & age 69 & age 72 \\
\hline 1.96 & 1.872 & 1.851 & 1.698 \\
$3.29 \%$ & $3 \%$ & $3.099 \%$ & $2.45 \%$ \\
$2.275 \%$ & $2.072 \%$ & $2.059 \%$ & $1.720 \%$
\end{tabular}

exponential discount rate, $\rho$

$2.072 \%$

$$
1.720 \%
$$

\begin{tabular}{lcccc}
\hline \hline \multicolumn{5}{c}{ Table 1b. Robustness of Results to Alternative Ages of Retirement } \\
\hline & & & & \\
& age 63 & age 66 (baseline) & age 69 & age 72 \\
\cline { 2 - 5 } overall time inconsistency & 4.1 years & 4.8 years & 6.5 years & 5.8 years \\
maximum debt & $32 \%$ & $46 \%$ & $58 \%$ & $66 \%$ \\
earlier saving & 4.3 years & 2.7 years & 1.5 years & 1.1 years \\
savings at retirement & $97 \%$ & $97 \%$ & $97 \%$ & $99 \%$ \\
All values are relative to the rational benchmark of exponential discounting. \\
\hline
\end{tabular}


Figure 1. Timepath of Planned Age of Retirement

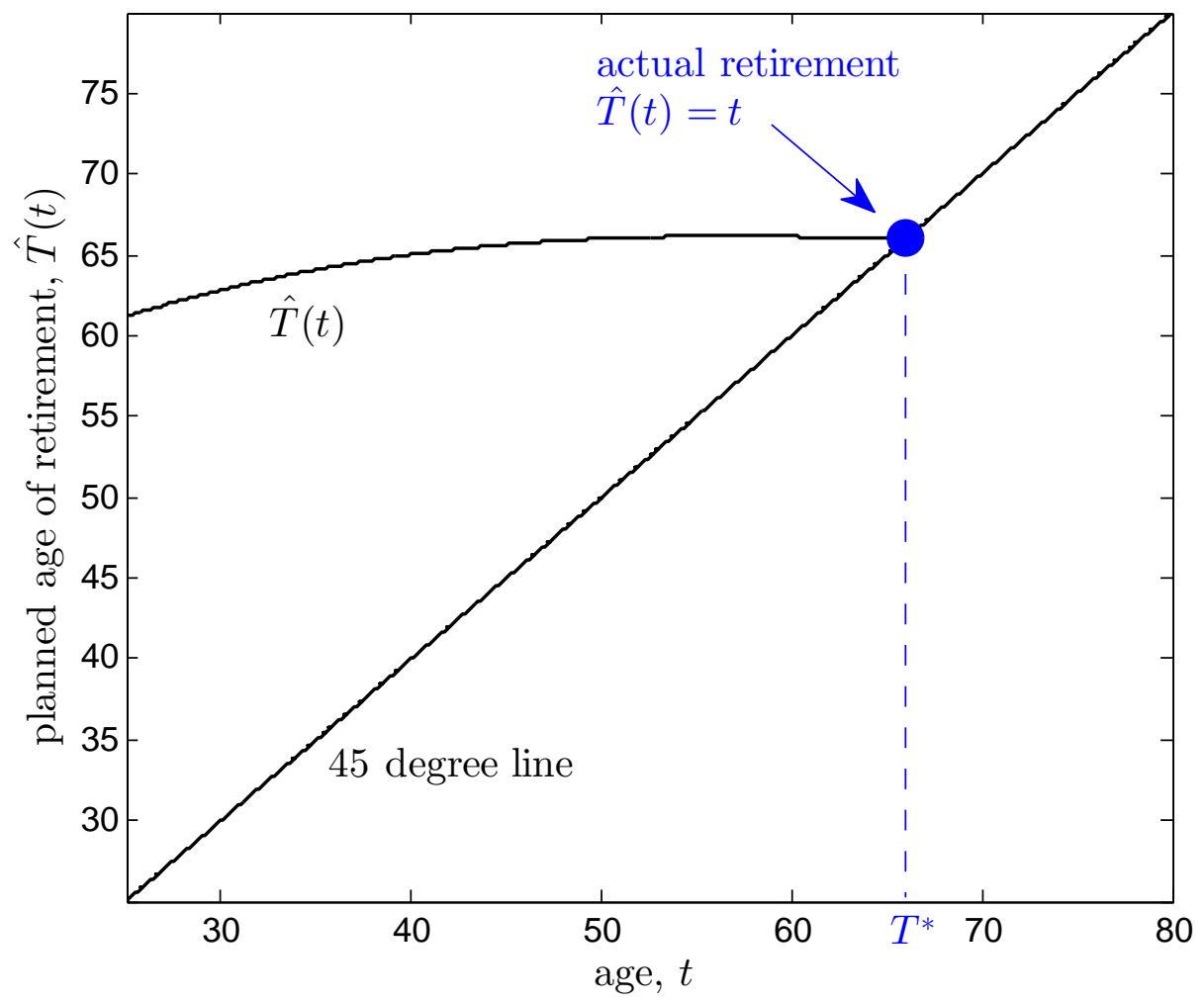

Note: We use $\beta=0.03$ and $\psi=1.872$.

Figure 2. Effect of Endogenous Retirement on Worklife Consumption

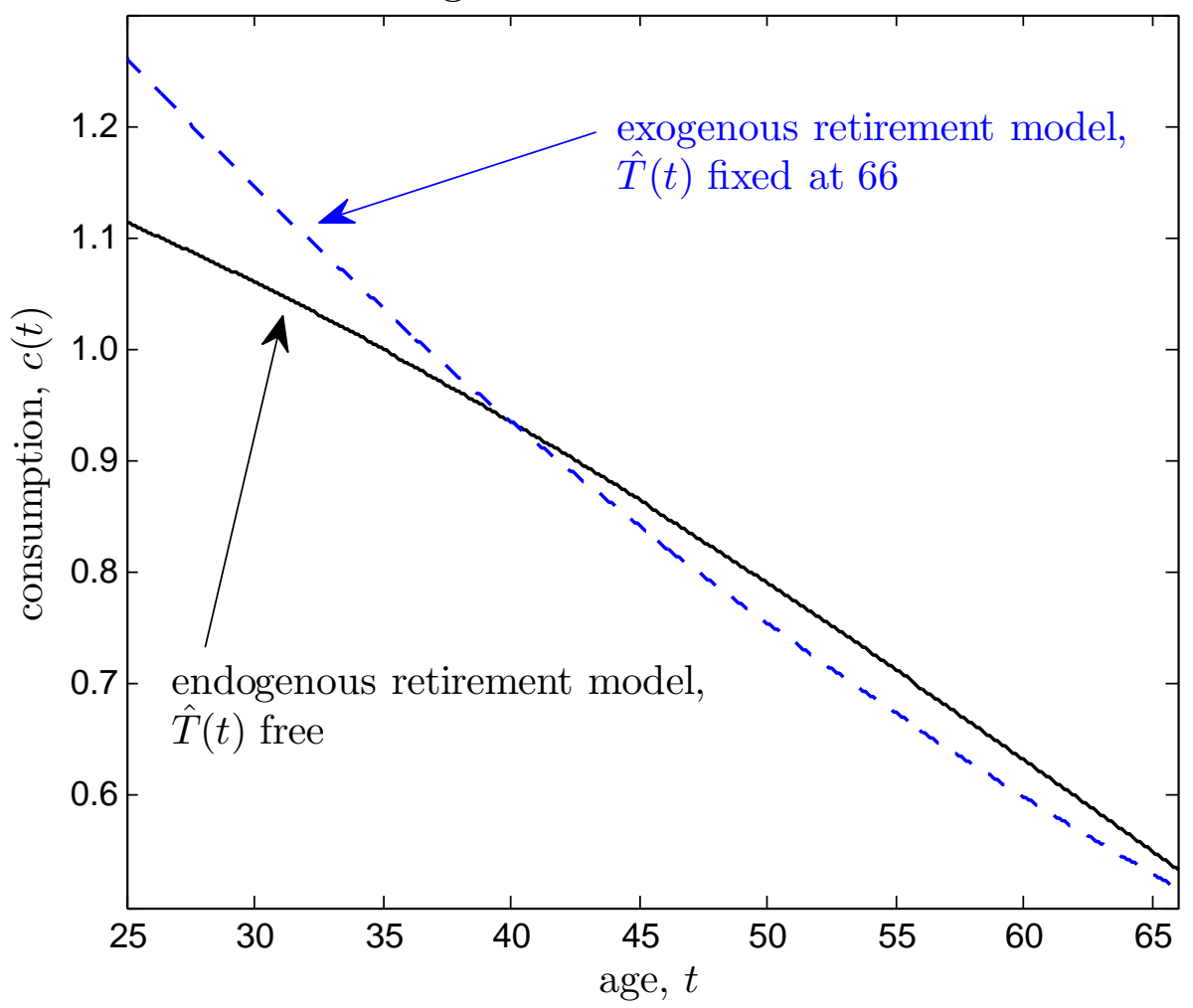

Note: In both cases, retirement is at age 66 . We use $\beta=0.03$ and $\psi=1.872$. 
Figure 3. Timepath of Planned Retirement for Alternative Parameterizations

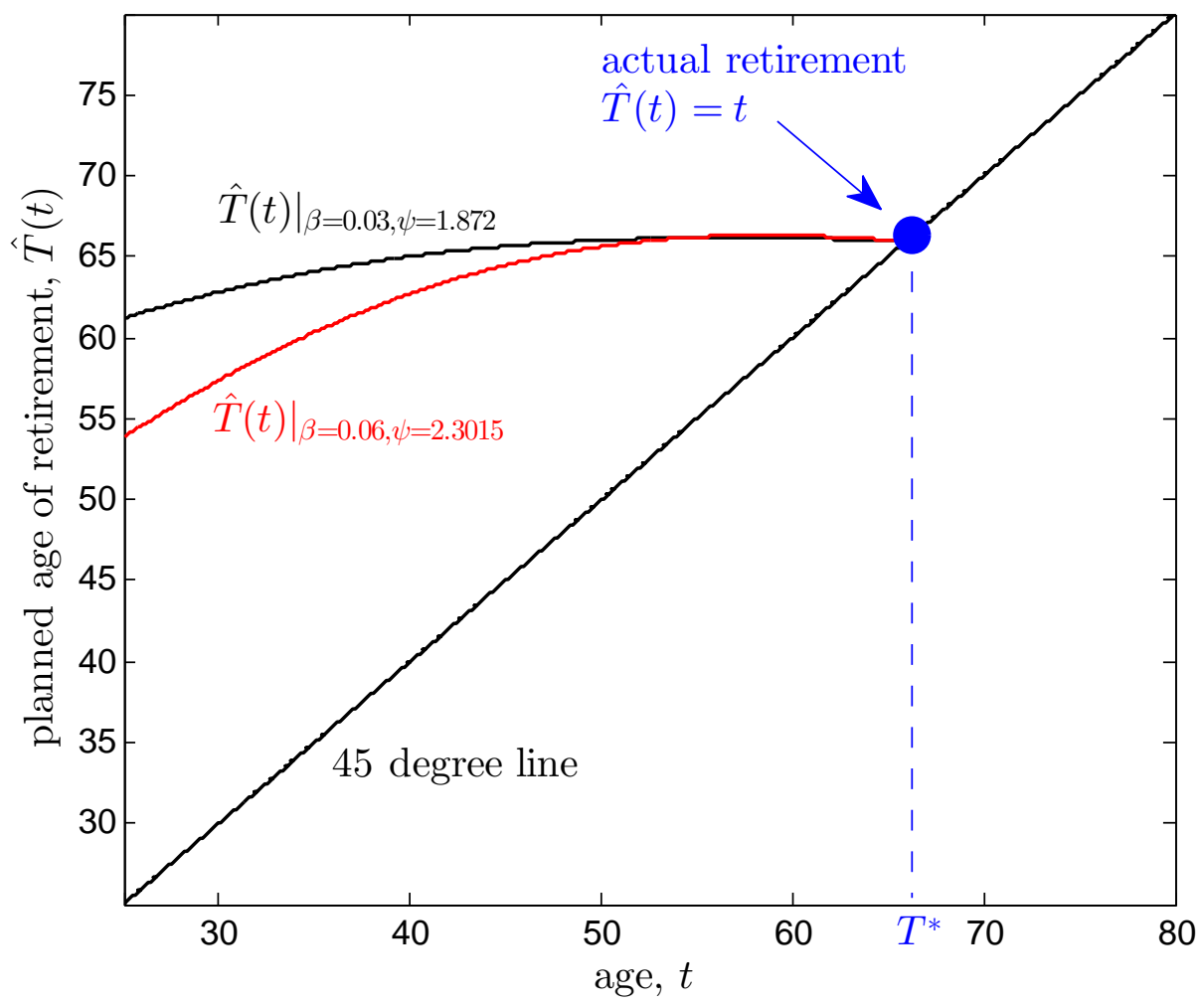

Figure 4. The Consumption Bias when Retirement is Exogenous

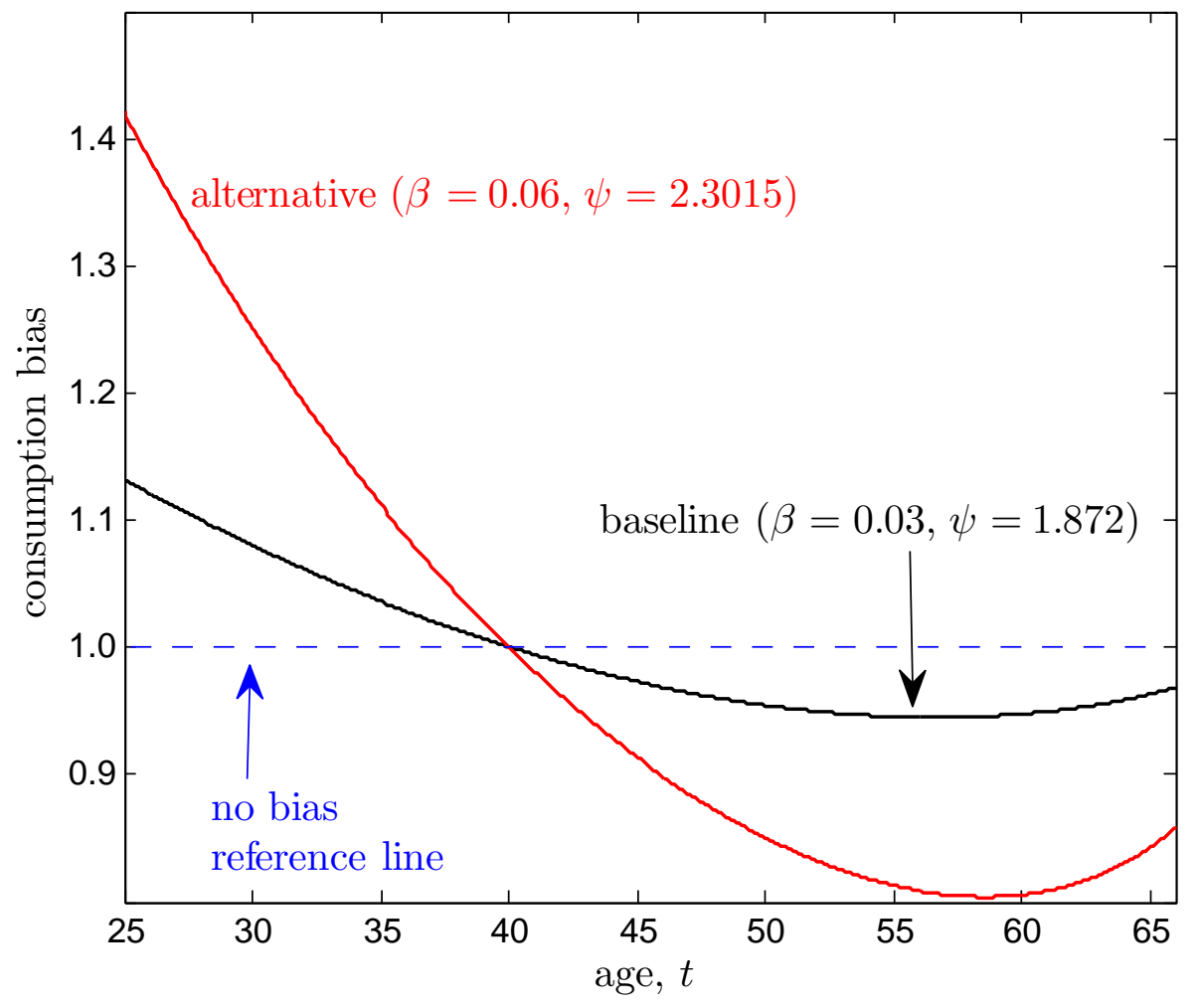


Figure 5. Comparison of Savings Account Balances over the Worklife

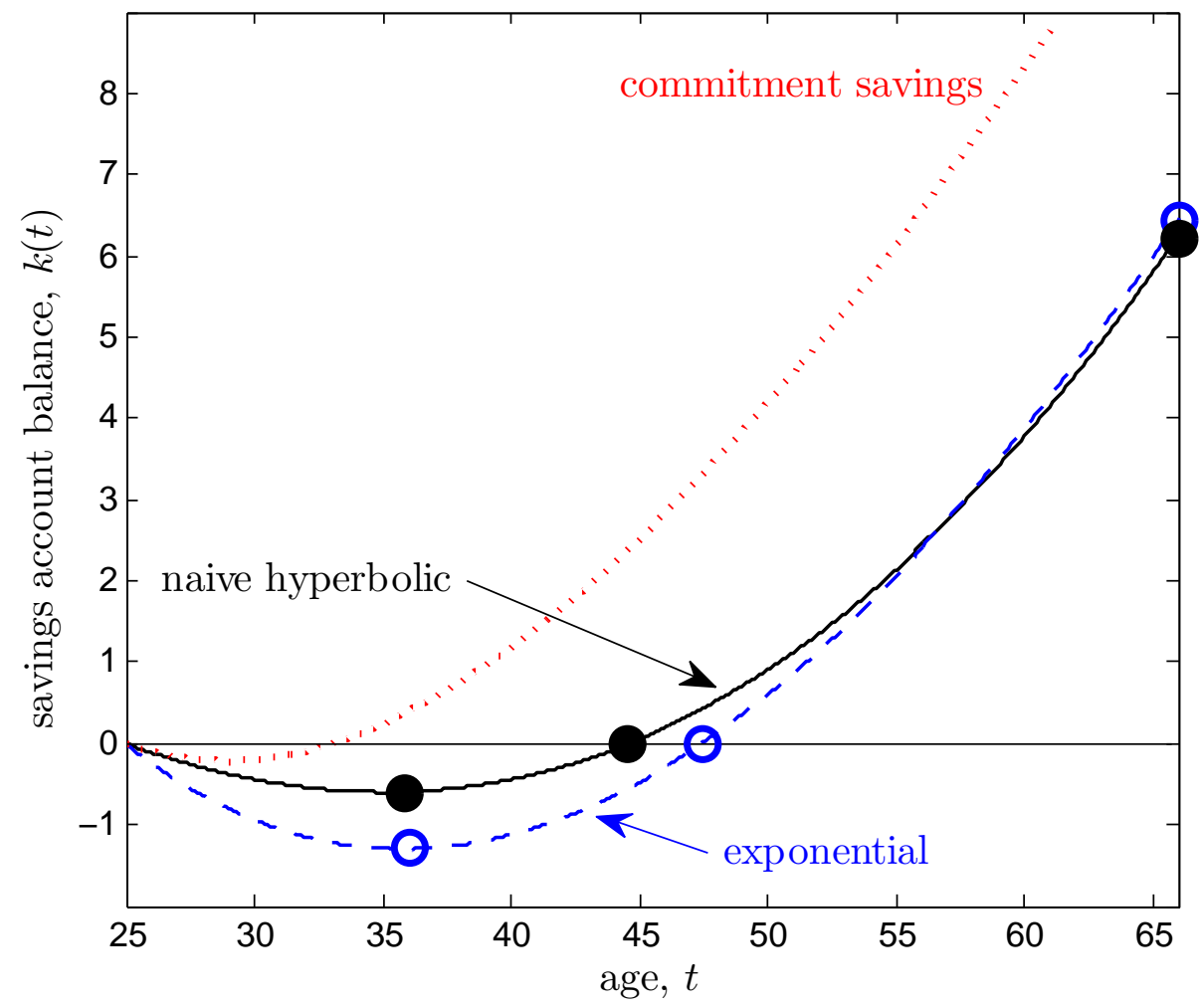

Note: Both discount functions are parameterized to ensure retirement occurs endogenously at age 66 . We use $\psi=1.872, \beta=0.03$, and $\rho=0.02072$.

Figure 6. The Role of Retirement Choice

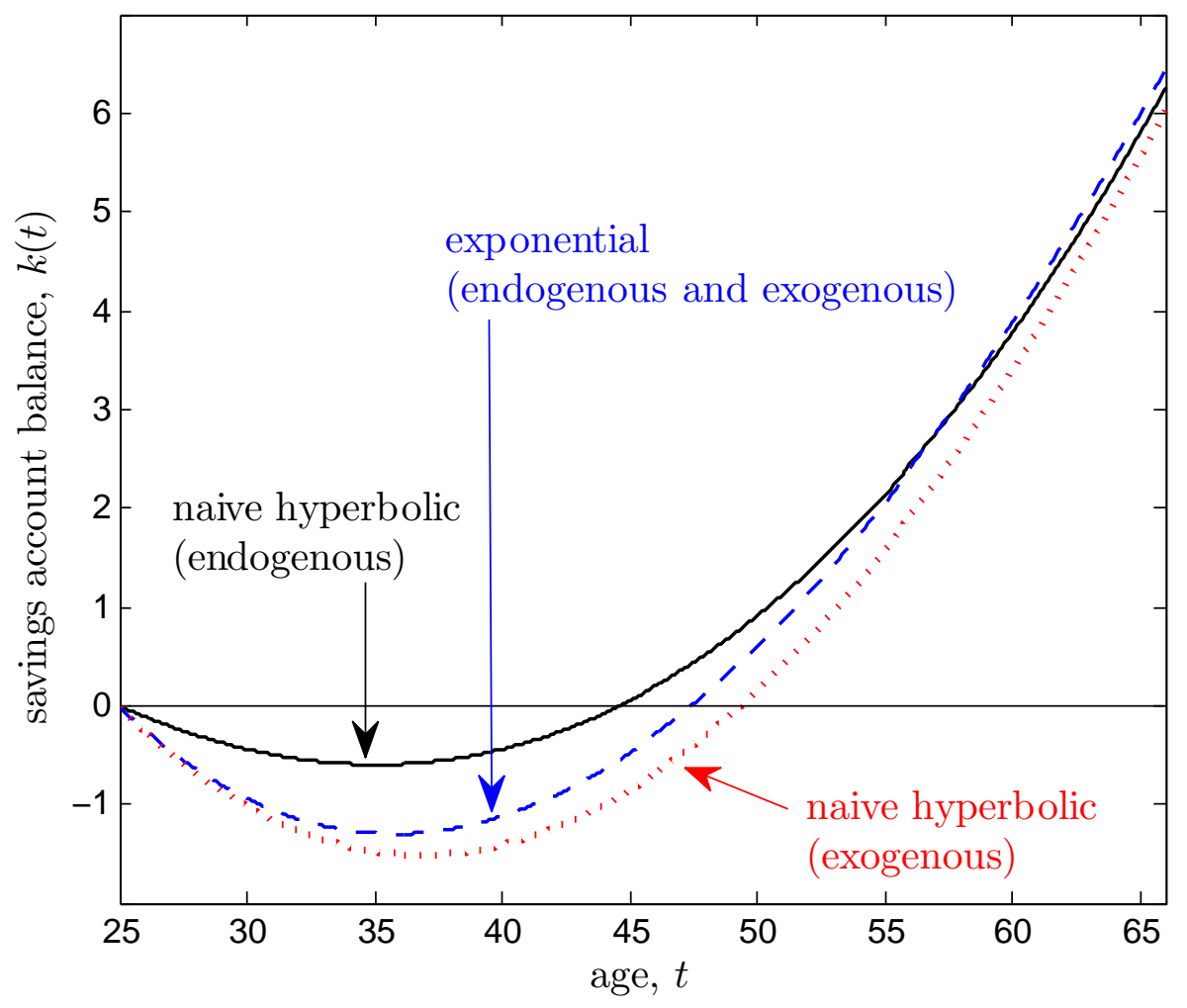

Note: We use $\psi=1.872, \beta=0.03$, and $\rho=0.02072$. 